AGRARIS: Journal of Agribusiness and Rural Development Research

Vol. 4 No. 1 J anuari -J uni 2018

\title{
Komparasi Usahatani Cabai Lahan Sawah Lereng Gunung Merapi dengan Lahan Pasir Pantai
}

https://doi.org/10.18196/agr.4156

\section{ABSTRACT}

The main production areas of chilli in Yogyakarta Province are in the wetland on the slopes of Mount Merapi and in the sandy coastal area. This research was intended to compare the use of production inputs, technical efficiency and performance of chilli farming in both areas. The research was conducted in Pakem sub-district and Panjatan sub-district. The number of respondents in this research were 30 farmers in every sub-district. Descriptive analysis, frontier analysis and revenue-cost ratio were used in this research. The results indicated that the use of production inputs, production, technical efficiency, and performance of chilli farming in the sandy coastal area was higher than that in the wetland. The technical efficiency in the wetland on the slopes of Mount Merapi was determined by the quantity of counselling while in the sandy coastal area was determined by the quantity of counselling and farmers' experience. The auction market in both areas proved able to increase the price of chilli. It is highly recommended that the extension officers need to be active in assisting farmers in both areas, especially related with chilli cultivation and processing technology.

Keywords: chilli, performance, sandy coastal area, technical efficiency, w etland.

\section{INTISARI}

Sentra produksi cabai di Daerah Istimewa Yogyakarta berada di lahan sawah lereng Gunung M erapi dan di lahan pasir pantai. Penelitian ini bertujuan untuk membandingkan penggunaan sarana produksi, efisiensi teknis dan kinerja usahatani di kedua wilayah. Penelitian ini dilaksanakan di Kecamatan Pakem dan Kecamatan Panjatan. Responden penelitian sebanyak 30 petani di setiap kecamatan. Analisis deskriptif, frontier, dan revenue-cost rasio digunakan pada penelitian ini. Hasil penelitian menunjukkan penggunaan sarana produksi, kuantitas produksi, efisiensi teknis, dan kinerja usahatani cabai lahan pasir pantai lebih tinggi daripada lahan sawah di lereng Gunung Merapi. Efisiensi teknis usahatani cabai di lahan sawah lereng Gunung Merapi dipengaruhi kuantitas penyuluhan sedangkan efisiensi teknis usahatani cabai di lahan pasir pantai dipengaruhi kuantitas penyuluhan dan pengalaman petani. Pasar lelang di kedua wilayah terbukti mampu meningkatkan harga cabai. Untuk pengembangan usahatani cabai di kedua wilayah diperlukan peran petugas penyuluh lapangan dalam mendampingi petani, terutama terkait teknologi budidaya dan pengolahan cabai.

Kata kunci: cabai, efisiensi teknis, kinerja, lahan pasir pantai, sawah.

\section{PENDAHULUAN}

C abai adalah komoditas strategis di Indonesia dan memiliki dampak cukup besar terhadap perekonomian. Kontribusi penting cabai diantaranya adalah memiliki nilai ekonomi tinggi, komoditas unggulan nasional, budaya Indone- 
sia menyukai makanan pedas, dan bahan baku industri (Andayani, 2016). Permintaan konsumsi cabai diprediksi terus meningkat seiring dengan pertumbuhan jumlah penduduk dan pertambahan industri (Bank Indonesia, 2007).

Peran cabai yang besar bagi perekonomian nasional tidak selaras dengan kondisi di tingkat petani. Fluktuasi harga adalah salah satu problem utama dan selalu menjadi sumber kekhawatiran petani cabai. Peningkatan produksi pada saat tertentu sering menyebabkan harga cabai turun drastis di pasaran (Istiyanti, 2010). Risiko perubahan harga juga semakin meningkat setelah adanya liberalisasi perdagangan (Nadezda, Dusan, \& Stefania, 2017). Di beberapa negara maju, salah satu cara pemerintah mengatasi fluktuasi harga adalah dengan asuransi ( $M$ arr, W inkel, Asseldonk, Lensink \& Bulte, 2016). Namun demikian, asuransi pertanian belum diterapkan di Indonesia sehingga fluktuasi harga sering merugikan petani cabai.

Fluktuasi harga cabai berpotensi dapat menurunkan kesejahteraan petani. $\mathrm{H}$ al ini dapat dilihat dari Nilai Tukar Petani (NTP) subsektor hortikultura. Namun begitu, NTP hortikultura di Daerah Istimewa Yogyakarta (DIY) terus meningkat walaupun ada fluktuasi harga cabai. Dari tahun 2008 sampai 2013, N TP petani hortikultura DIY naik dari 105,00 menjadi 138,00 . Nilai tersebut mengindikasikan usahatani cabai petani DIY semakin baik.

Produksi tertinggi cabai di DIY berlokasi di Kabupaten Kulon Progo dan Kabupaten Sleman. Produksi cabai di dua lokasi tersebut mencapai $72 \%$ dan $19 \%$ dari total produksi cabai di DIY. U niknya, kedua sentra produksi tersebut memiliki karakteristik lahan yang sangat berbeda. Sentra budidaya cabai di Kulon Progo adalah lahan pasir pantai sedangkan sentra budidaya cabai di Sleman adalah lahan sawah di lereng Gunung M erapi.

Budidaya cabai di lahan pasir pantai sangat menguntungkan petani dan memiliki keunggulan kompetitif (Istiyanti, Khasanah, \& Anjarwati, 2015). Keunggulan kompetitif ini dapat dicapai salah satunya karena petani menjual panen ke pasar lelang (Kuntadi \& Jamhari, 2012). $\mathrm{H}$ arga yang diperoleh di pasar lelang jauh lebih tinggi dibandingkan dengan harga ketika petani menjual ke pedagang pengepul. $\mathrm{H}$ al ini yang menyebabkan kontribusi pendapatan cabai merupakan yang tertinggi bagi petani pasir pantai di setiap musim tanam (W idodo, 2015). Hal serupa juga terjadi dengan usahatani cabai di lereng G unung M erapi yang menguntungkan serta petani menerima harga yang layak dari aktivitas pemasaran (Istiyanti, 2010).

Penelitian ini bertujuan membandingkan penggunaan sarana produksi, efisiensi teknis dan kinerja usahatani cabai lahan sawah di lereng G unung M erapi dengan usahatani cabai di lahan pasir pantai Kulon Progo karena kedua lokasi mampu menghasilkan NTP hortikultura tertinggi di Pulau Jawa serta keuntungan besar bagi petani. Perbandingan usahatani cabai kedua wilayah juga berguna untuk memperbaiki kekurangan usahatani cabai pada kedua lokasi. A palagi penelitian yang ada selama ini seluruhnya hanya meneliti di salah satu lokasi pada rentang waktu yang tidak bersamaan.

\section{METODE PENELITIAN}

Penelitian dilaksanakan di Kecamatan Pakem, Kabupaten Sleman dan Kecamatan Panjatan, Kabupaten Kulon Progo, D aerah Istimewa Yogyakarta (D IY). Kedua kecamatan dipilih dengan metode purposive sampling karena merupakan sentra produksi cabai merah di DIY serta mewakili wilayah usahatani cabai pada lahan sawah di lereng Gunung M erapi dan usahatani cabai di lahan pasir pantai. Responden dalam penelitian ini sebanyak 60 petani, masing-masing 30 petani di Kecamatan Pakem dan Kecamatan Panjatan. Responden dipilih dengan menggunakan simple random sampling dari populasi petani anggota kelompok tani $\mathrm{N}$ gudi Rejeki dan kelompok tani N gemput di Kecamatan Pakem serta kelompok tani Gisik Pranaji di Kecamatan Panjatan. Pemilihan kelompok tani tersebut berdasarkan rekomendasi dari penyuluh lapangan karena merupakan kelompok tani dengan produksi cabai tertinggi di tiap kecamatan. Pengambilan data dilakukan dengan metode wawancara menggunakan kuesioner yang dilaksanakan pada bulan M ei sampai dengan A gustus 2017.

$M$ etode yang digunakan untuk mengetahui penggunaan sarana produksi usahatani cabai adalah analisis deskriptif berdasarkan hasil wawancara petani. U ntuk mengetahui efisiensi teknis digunakan analisis stochastic frontier yang mampu memperhitungkan dampak dari faktor tidak terkontrol pada model deterministic frontier (O uattara, 2012). M odel tersebut dianalisismenggunakan software frontier 4.1c versi Technical Efficiency Effect Model. Model ini dapat dirumuskan sebagai berikut:

$$
T E i=\frac{Y_{a}}{Y_{f}}
$$

Dalam persamaan ini $\mathrm{TE}_{i}$ menunjukkan efisiensi teknis usahatani cabai, $Y_{a}$ menunjukkan produksi cabai, dan $Y_{f}$ menunjukkan estimasi produksi menggunakan stochastic frontier.

M odel stochastic frontier menunjukkan hubungan antara output dengan input, variabel error, dan inefisiensi (Coelli, Rao, O 'D onnell, \& Battes, 2005). Pada penelitian ini fungsi 
produksi stochastic frontier usahatani cabai diduga dengan menggunakan metodeEstimasi M aksimum Likelihood (MLE) sebagai berikut:

$$
\begin{aligned}
\operatorname{Ln} Q= & \beta_{0}+\beta_{1} \operatorname{Ln} X_{1}+\beta_{2} \operatorname{Ln} X_{2}+\beta_{3} \operatorname{Ln} X_{3}+ \\
& \beta_{4} \operatorname{Ln} X_{4}+\beta_{5} \operatorname{Ln} X_{5}+\beta_{6} \operatorname{Ln} X_{6}+\beta_{7} \operatorname{Ln} X_{7}+\beta_{8} \\
& \operatorname{Ln} X_{8}+e-\mu
\end{aligned}
$$

Dalam model ini $Q$ adalah produksi $(\mathrm{kg}), \mathrm{X}_{1}$ adalah luas lahan $\left(\mathrm{m}^{2}\right), \mathrm{X}_{2}$ adalah jumlah tenaga kerja (HKO) hari kerja orang, $X_{3}$ adalah jumlah benih $(\mathrm{kg}), X_{4}$ adalah jumlah pupuk urea $(\mathrm{kg}), X_{5}$ adalah jumlah pupuk TSP $(\mathrm{kg}), X_{6}$ adalah jumlah pupuk ZA $(\mathrm{kg}), X_{7}$ adalah jumlah pupuk organik $(\mathrm{kg}), X_{8}$ adalah jumlah pestisida (It), eadalah nilai error, dan $\mu$ adalah inefisiensi.

U ntuk mengetahui faktorfaktor yang mempengaruhi efisiensi teknis digunakan analisis regresi berganda sebagai berikut:

\section{TE $_{i} \quad=\boldsymbol{\beta}_{0}+\boldsymbol{\beta}_{1}$ Pylh $+\boldsymbol{\beta}_{2}$ Pdki $+\boldsymbol{\beta}_{3}$ Pglm}

$\mathrm{TE}_{\mathrm{i}}$ adalah nilai efisiensi tekniscabai lahan sawah di lereng Gunung M erapi atau usahatani cabai di lahan pasir pantai Kulon Progo, Pylh adalah kuantitas penyuluhan yangdiikuti petani, Pdki adalah tingkat pendidikan formal, dan Pglm adalah pengalaman berusahatani.

Kinerja usahatani cabai dianalisis dengan menggunakan analisis pendapatan dan menghitung $\mathrm{R} / \mathrm{C}$ rasio, dengan kriteria sebagai berikut: (1) A pabila nilai $\mathrm{R} / \mathrm{C}$ rasio lebih kecil dari 1 maka usahatani tidak layak karena mengalami kerugian, (2) A pabila nilai $\mathrm{R} / \mathrm{C}$ rasio sama dengan 1 maka usahatani impas, dan (3) A pabila nilai $\mathrm{R} / \mathrm{C}$ rasio lebih besar dari 1 maka usahatani layak karena menguntungkan.

\section{HASIL DAN PEMBAHASAN}

M usim tanam cabai di DIY cukup bervariasi. Mayoritas petani di lahan pasir pantai menanam cabai pada bulan $M$ aret, tetapi juga terdapat beberapa petani yang menanam cabai pada bulan Februari atau A pril. Sedangkan mayoritas petani di lereng $G$ unung M erapi umumnya menanam cabai pada pertengahan tahun antara bulan A pril sampai Juni. $\mathrm{N}$ amun terdapat sebagian kecil petani yang menanam di bulan September dan N ovember. Rata-rata petani di kedua lokasi dapat melakukan petik cabai sebanyak 8 hingga 15 kali pada saat musim panen.

\section{ALOKASI PENGGUNAAN SARANA PRODUKSI CABAI}

Faktor produksi utama yang digunakan petani adalah lahan. Petani cabai di kedua wilayah memiliki luas penguasaan dan status kepemilikan lahan yang berbeda-beda.

\begin{tabular}{|c|c|c|c|}
\hline \multirow[b]{2}{*}{$\mathrm{Nb}$} & \multirow[b]{2}{*}{$\begin{array}{l}\text { Status } \\
\text { Keperilikan }\end{array}$} & \multicolumn{2}{|c|}{ Lueslathan(ha) } \\
\hline & & $\begin{array}{l}\text { LahenSanth } \\
\text { LerengCanurg } \\
\text { Meap (Senz) }\end{array}$ & $\begin{array}{c}\text { LahanPair } \\
\text { Patai (Kulan } \\
\text { Pogo) }\end{array}$ \\
\hline 1 & MlikSerdir & C,12 & C,2k \\
\hline 2 & Menjene & $C, O F$ & $c, 2$ \\
\hline 3 & Menjekp & 0,05 & 0,00 \\
\hline & Tdd & 0,25 & 0,51 \\
\hline
\end{tabular}

\section{TABH1 PENGASANLAHANPEIAN CABA D LAHANSANAHLEENG GNNGMEAP DANLAHANPASRPANIA}

Status kepemilikan lahan petani terbagi dalam tiga kategori, yaitu lahan milik sendiri, sewa dan sakap. D ampak dari statuskepemilikan lahan tersebut adalah biaya yang harus dikeluarkan petani. Untuk lahan milik sendiri, petani harus mengeluarkan biaya pajak tanah. Sedangkan petani yang menyewa lahan harus mengeluarkan biaya sewa dan petani yang menyakap lahan harus membagi hasil panen dengan pemilik lahan. D ari ketiga status kepemilikan Iahan, petani yang memiliki lahan sendiri mampu mengeluarkan biaya penggunaan lahan lebih kecil daripada petani yang menyewa atau menyakap lahan.

Tabel 1 menunjukkan kepemilikan lahan petani di lahan pasir pantai lebih luas dibandingkan petani lahan sawah lereng Gunung M erapi. Hal ini karena harga beli dan sewa lahan pasir pantai di Kulon Progo lebih murah daripada lahan sawah di Sleman. Alasan kedua karena tingkat persaingan penggunaan lahan pasir pantai lebih rendah daripada lahan sawah di lereng Gunung M erapi. Lahan sawah di Sleman tidak mungkin untuk diperluas bahkan memiliki kecenderungan semakin menyusut karena persaingan dengan penggunaan lahan untuk pemukiman dan kegiatan perdagangan. Sedangkan di lahan pasir pantai, perluasan lahan untuk budidaya cabai masih sangat memungkinkan karena tidak digunakan untuk pemukiman atau kepentingan lain. D engan kepemilikan lahan yanglebih luas, maka petani lahan pasir pantai dapat menghasilkan produksi cabai lebih tinggi daripada petani di lereng $\mathrm{G}$ unung M erapi.

Faktor produksi kedua yang dibutuhkan dalam usahatani adalah tenaga kerja, baik dalam keluarga maupun luar keluarga. Tenaga kerja dalam usahatani cabai sebagian besar adalah tenaga kerja dalam keluarga. Tenaga kerja dalam 
keluarga dialokasikan untuk kegiatan pemeliharaan tanaman (pemupukan, penyemprotan pestisida dan menyiangi gulma) dan pengairan sedangkan tenaga kerja luar keluarga dialokasikan pada kegiatan pengolahan lahan dan panen. Tabel 2 menunjukkan bahwa alokasi tenaga kerja dalam keluarga lebih besar daripada tenaga kerja luar keluarga karena petani cabai memiliki modal terbatas dan masih banyak petani yang berusia produktif sehingga lebih banyak melakukan aktivitas usahatani secara mandiri.

\section{TABH 2 BAAABAAPE LAHANSAMAHLEENGGNUNGMAF DANLAHANPASRPANIA PR IETAR}

\begin{tabular}{|c|c|c|c|}
\hline $\mathrm{Nb}$ & JerisTeragaKeja & $\begin{array}{l}\text { Lansanthlereng } \\
\text { GanngMeraj } \\
\text { (Senan) }\end{array}$ & $\begin{array}{l}\text { LahenPairPata } \\
\text { (KuonPog) }\end{array}$ \\
\hline \multirow[t]{7}{*}{1} & DAamKAlarga(HO) & 209,84 & 472,70 \\
\hline & Penyenaian & 3,60 & 11,84 \\
\hline & Pengdahenlaken & 28,2 & 12,01 \\
\hline & Peneneman & 9,36 & 18,72 \\
\hline & Pentliheran & 115,28 & 53,66 \\
\hline & Pengairan & 416 & 290,24 \\
\hline & Paren & 49,32 & 26,22 \\
\hline \multirow[t]{7}{*}{2} & LuerKÁurga(HO) & 147,88 & 149,06 \\
\hline & Penyenaian & Q, & 5,04 \\
\hline & Pengdahenlaten & 80,32 & 12,54 \\
\hline & Perenenan & $6 ఱ 8$ & 17,25 \\
\hline & Pendihaæan & 872 & 8,06 \\
\hline & Pengiran & $0, \infty$ & 4,19 \\
\hline & Paren & 52,16 & 101,98 \\
\hline \multicolumn{2}{|c|}{ Tdd TenagaKeja(HO) } & 35,72 & 561,76 \\
\hline
\end{tabular}

Sumber: Analisis Data Primer (2017)

Penggunaan tenaga kerja di lahan pasir pantai Kulon Progo lebih intensif karenaluasan lahan lebih tinggi daripada usahatani cabai di sawah lereng Gunung M erapi. Alokasi tenaga kerja dalam keluarga di lahan pasir pantai utamanya untuk aktivitas pengairan karena pada wilayah ini sangat mudah terjadi infiltrasi air ke lapisan tanah dalam dan laju penguapan yang tinggi sehingga menyebabkan tanaman kekurangan air serta mengganggu proses produksi. U ntuk wilayah lahan sawah lereng G unung M erapi, alokasi tenaga kerja dalam keluarga paling besar pada kegiatan pemeliharaan tanaman. $\mathrm{Hal}$ ini karena cabai merupakan tanaman yang membutuhkan perawatan cukup banyak dan membutuhkan tenaga kerja yang besar pula.
Tenaga kerja luar keluarga pada lahan pasir pantai difokuskan untuk panen sedangkan pada lahan sawah lereng Gunung Merapi difokuskan untuk pengolahan lahan. Penggunaan tenaga kerja luar keluarga untuk kegiatan panen di lahan pasir pantai lebih besar daripada lahan sawah di lereng G unung Merapi karena jumlah tanaman cabai per hektar di lahan pasir pantai yang lebih banyak. Namun petani di lahan pasir pantai mampu mengalokasikan tenaga kerja luar keluarga lebih rendah untuk kegiatan pengolahan lahan karena para petani tersebut juga menggunakan alat mesin pertanian sehingga kegiatan ini menjadi lebih cepat dan membutuhkan tenaga kerja lebih sedikit daripada petani di lereng G unung M erapi.

\section{TABH 3 BAAARATAPENGONANSABANAPROUKS USA-AAN CABAD

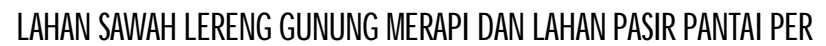 IETAR}

\begin{tabular}{|c|c|c|c|}
\hline $\mathrm{Nb}$ & $\begin{array}{c}\text { JeisSara } \\
\text { Prodks }\end{array}$ & $\begin{array}{l}\text { LatenSenthlereng } \\
\text { GrungMeap } \\
\text { (Senan) }\end{array}$ & $\begin{array}{l}\text { LatanPair } \\
\text { Patai (Kulan } \\
\text { Poog) } \\
\end{array}$ \\
\hline 1 & Berih(bjij) & 13823,33 & $33,22,22$ \\
\hline \multirow[t]{8}{*}{2} & Ppak & & \\
\hline & Uka(kg) & & 32,6 \\
\hline & $T S(k g)$ & 25,35 & $123,5=$ \\
\hline & $\mathrm{KC}(\mathrm{kg})$ & 19,33 & 41,83 \\
\hline & $\mathbb{Z}(\mathrm{kg})$ & $72, \infty$ & 296,41 \\
\hline & NFPhonsta(kg) & 396,0 & 239,28 \\
\hline & NFKMtiaa(kg & 145,87 & $179,6 /$ \\
\hline & Ogarik (kg) & 1.B32,9 & $1 \varepsilon .586,01$ \\
\hline \multirow[t]{3}{*}{3} & PestisidE & & \\
\hline & Car (nh) & $1.298,80$ & $1.68,6 \subset$ \\
\hline & Padt $(k g)$ & 3,40 & 4,45 \\
\hline
\end{tabular}

Tabel 3 menunjukkan secara umum penggunaan sarana produksi di lahan pasir pantai lebih tinggi daripada lahan sawah di lereng G unung M erapi. Artinya usahatani cabai di lahan pasir pantai diusahakan secara lebih intensif daripada usahatani cabai pada lahan sawah di lereng G unung M erapi. Benih cabai yang digunakan oleh petani di kedualokasi cukup bervariasi. Petani di lahan sawah lereng Gunung M erapi memilih menggunakan varietas Keropi, Rimbun, Twist dan Kencana, sedangkan petani di lahan pasir pantai menggunakan varietas $\mathrm{H}$ elix karena cepat berbuah serta cocok ditanam di dataran rendah. Penggunaan benih cabai di lahan pasir pantai lebih tinggi daripada usahatani cabai di lereng G unung M erapi. Namun begitu, penggunaan benih di lahan pasir pantai Kulon Progo telah efisien dan tidak perlu ditambah atau dikurangi (Istiyanti, Khasanah, \& Anjarwati, 2015). 
Pupuk yang digunakan petani dalam usahatani cabai diantaranya urea, TSP, KCL, ZA, NPK Phonska, NPK M utiara, dan pupuk organik. Pupuk organik sebagai pupuk dasar sangat penting karena membuat tanah menjadi lebih subur dan meningkatkan unsur hara serta dapat memperbaiki struktur tanah. Pupuk kimia dengan penggunaan terendah adalah pupuk urea karena hanya digunakan sebagai pupuk pelengkap apabila kondisi tanaman terlihat kurang segar. Pupuk kimia utama yang digunakan untuk pemupukan cabai adalah pupuk N PK, baik phonska maupun M utiara, sebab kandungan haranya lengkap untuk tanaman cabai. Penggunaan pupuk di lahan pasir pantai juga sangat tinggi karena kondisinya tidak subur serta serapan hara tanaman lambat akibat pupuk mudah hilang terinfiltrasi bersama air kelapisan tanah yanglebih dalam (Al-O mran, Falatah, Sheta, \& Al-H arbi, 2004). Alasan kedua adalah promosi gencar dari agen pupuk yang membujuk petani menggunakan produk tersebut sehingga petani terkadang menggunakan pupuk di atas dosis anjuran.

Petani umumnya menggunakan pestisida dengan kuantitas tinggi karena intensitas serangan jamur Colletotrichum capsici yangmenyebabkan antraknosa atau busuk buah dan serangan virus kuning. Tabel 3 menunjukkan bahwa penggunaan pestisida di lahan pasir pantai lebih tinggi dibandingkan di lahan sawah lereng $G$ unung M erapi. Penyebab utama kondisi ini adalah promosi masif dari agen pestisida yang mampu mengajak petani mengunakan pestisida untuk pengendalian organisme pengganggu tanaman.

\section{EFISIENSI TEKNIS USAHATANI CABAI}

$N$ ilai sigma-squared $\left(o^{2}\right)$ yang diperoleh dari pendugaan dengan metode Estimasi Maksimum Likelihood baik usahatani cabai di lahan sawah lereng Gunung M erapi maupun lahan pasir pantai signifikan pada tingkat kepercayaan $99 \%$ dan lebih besar dari nol atau terdapat pengaruh inefisiensi teknis pada variasi jumlah produksi cabai yang dihasilkan. $\mathrm{H}$ al ini juga diperkuat dengan nilai gamma (ã) yang menunjukkan perbedaan antara produksi cabai faktual dengan potensi produksi cabai maksimum yang dapat dicapai, 99,9\% di lahan sawah lereng $G$ unung M erapi dan $24,00 \%$ di lahan pasir pantai disebabkan oleh efek in efisiensi teknis, sebagaimana ditunjukkan dalam Tabel 4.

$\mathrm{H}$ asil estimasi produksi cabai di lahan sawah lereng Gunung Merapi menunjukkan bahwa penambahan luas lahan, jumlah benih dan jumlah pestisida Bion $\mathrm{M}$ mampu meningkatkan produksi. $\mathrm{H}$ al ini menunjukkan penggunaan tiga faktor produksi tersebut belum efisien. Jumlah benih cabai per hektar lahan di lereng Gunung M erapi sebanyak 13.823 biji dan masih di bawah standar ideal sebesar 18-20 ribu biji sehingga potensi untuk meningkatkan jumlah pertanaman cabai masih sangat besar (Dinas Pertanian Provinsi D aerah Istimewa Yogyakarta, 2009). Selain itu, ada pula faktor produksi yang sudah tidak efisien yakni jumlah tenaga kerja dan jumlah pupuk ZA sehingga penambahan keduanya menyebabkan penurunan produksi.

\section{TABH 4 EIIMAS MAKMMMUKB UHODHNG PROUKS FONIIR STOKASTIKLSAHATN CBA D LAHANSAMAHIEENGG NNGMEAAF}

\begin{tabular}{|c|c|c|c|}
\hline Vaiabd & Kœisier & StandarEro & t-Ratic \\
\hline Kastata & 1,268 & $0,8 / 5$ & $1,449^{5}$ \\
\hline Leslatan & 0,109 & 0,009 & $11,743^{*+*}$ \\
\hline JuntehTenagaKeja & $-0,3 / 5$ & 0,166 & $-2,262^{*}$ \\
\hline JuntehBerit & 0,978 & 0,042 & $23,192^{* * * *}$ \\
\hline JuntehTS & 0,025 & 0,056 & $0,45 C^{\mathrm{ns}}$ \\
\hline Junteh $\mathbb{Z}$ & $-0,077$ & 0,044 & $-1, T \angle \varepsilon^{*}$ \\
\hline JuntehRpak Gogrik & $-0,234$ & 0,015 & $-1,554^{\mathrm{s}}$ \\
\hline JuntehPest Banex & 0,019 & 0,011 & $1,65^{5}$ \\
\hline JuntehPest Atrad & 0,013 & 0,019 & $0,665^{5}$ \\
\hline JuntedPest BanM & $0,0 / 5$ & 0,025 & $3,012^{* * *}$ \\
\hline SglatSqued & 0,667 & 0,089 & $7,464^{\text {tox }}$ \\
\hline Gamm & 0,999 & $0,331 E=04$ & $0,301 \mathbb{E}+05^{* * *}$ \\
\hline MentEficiercy & 0,574 & & \\
\hline
\end{tabular}

\footnotetext{
Keterangan:

*** signifikan pada $\alpha=0,01$

** signifikan pada $\alpha=0,05$

* $\quad$ signifikan pada $\alpha=0,10$

ns tidak signifikan
}

Sumber: Analisis Data Primer (2017)

Petani di wilayah ini tidak menggunakan pupuk urea

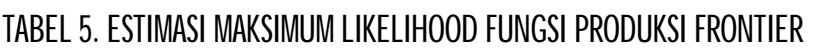
STOKASTIKL SAHAAN CABA D LAHANPASRPANIA KUONPRCO

\begin{tabular}{|c|c|c|c|}
\hline Veriabd & Kœisier & StanderEiro & t-Pedjc \\
\hline Konstata & 6,799 & 1,144 & $4,706^{* *}$ \\
\hline Lueslatan & 0,639 & 0,117 & $5,431^{* * * *}$ \\
\hline JuntehTenagaKeja & 0,173 & 0,132 & $1,305^{5}$ \\
\hline JuntehBarit & 0,151 & 0,171 & $1,357^{1 \mathrm{~s}}$ \\
\hline JuntehUte & 0,021 & $0,02 \varepsilon$ & $0,95^{\mathrm{ns}}$ \\
\hline Junteh $\mathbb{~}$ & $0,0 / 2$ & 0,026 & $2, \pi E^{* * *}$ \\
\hline Junteh $\mathbb{Z}$ & $-0,019$ & 0,037 & $-0,514^{r s}$ \\
\hline JuntehRpakOggrik & $-0,054$ & 0,020 & $-2,643^{*}$ \\
\hline JuntehPest Banex & $-0,020$ & 0,018 & $-1,108^{5}$ \\
\hline JuntedPest Antrad & $-0,005$ & 0,013 & $-0,413^{5}$ \\
\hline Junthed Bet BonM & 0,008 & 0,019 & $0,429^{5}$ \\
\hline SggmSqued & 0,118 & 0,02 & $5,444^{(* * *}$ \\
\hline Comma & 0,240 & 0,044 & $0,950 E+01^{* * *}$ \\
\hline Mentfifiercy & 0,998 & & \\
\hline
\end{tabular}

Sumber: Analisis Data Primer (2017) 


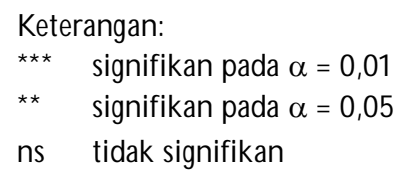

H asil estimasi produksi cabai di lahan pasir pantai Kulon Progo menunjukkan bahwa penambahan luas lahan dan jumlah pupuk TSP dapat meningkatkan produksi sedangkan penambahan jumlah pupuk organik menyebabkan penurunan produksi. O bservasi di lapangan menunjukkan bahwa penambahan pupuk TSP memang diperlukan karena penggunaan pupuk tersebut saat ini adalah 123,53 kg per ha sedangkan rekomendasi ideal yakni $200 \mathrm{~kg}$ per ha (Dinas Pertanian Provinsi D aerah Istimewa Yogyakarta, 2009). Selain itu, penambahan pupuk organik sudah tidak diperlukan bagi lahan pasir pantai, karena petani telah menambahkan pupuk organik terlalu banyak (18,5 ton per ha) dan bahkan di atas rekomendasi ideal budidaya cabai (5 ton per ha) (Kementrian Pertanian Indonesia, 2010).

$\mathrm{N}$ ilai rata-rata efisiensi teknis (mean efficiency) petani di lahan pasir pantai lebih tinggi daripada petani di lahan sawah lereng $\mathrm{G}$ unung $\mathrm{M}$ erapi. $\mathrm{H}$ al ini menunjukkan penggunaan sarana produksi cabai di lahan pasir pantai telah efisien sehingga mampu menghasilkan produksi cabai lebih tinggi yakni 6.624,18 kg per hektar sedangkan di lahan sawah lereng Gunung M erapi adalah $3.102,93 \mathrm{~kg}$ per hektar. Namun begitu, nilai efisiensi teknis rata-rata (mean efficiency) usahatani cabai di kedua wilayah masih kurang dari 1 atau belum mencapai produktivitas maksimum sehingga perlu dilakukan berbagai perbaikan dengan mengoptimalkan faktor yang mempengaruhi efisiensi teknis.

\section{TABH 6 FAKTRRYANGMMENGAR H TSEQB TENSU SAHAAN CABA DLAHANSAAHLEENGGNNGMEAA}

\begin{tabular}{|c|c|c|c|}
\hline Veriads & kofisier & Stander Erra & t-Ratic \\
\hline Konstata & 3,582 & 0,707 & $5,063^{* *}$ \\
\hline KartitasPenylurar & $-0,172$ & 0,06 & $-1,774^{*}$ \\
\hline TingktPenddlkanFora & $-0,03 x$ & 0,272 & $-0,14 C^{n s}$ \\
\hline PengdananBerustatai & 0,094 & 0,156 & $0,601^{\text {ms }}$ \\
\hline AdutedF ${ }^{2}$ & & & $\mathrm{C}, 20 \mathrm{C}$ \\
\hline PdadablitasFhiturg & & & $1,940^{\circ}$ \\
\hline
\end{tabular}

Keterangan:

*** = Signifikan pada $\alpha=0,01$

* = Signifikan pada $\alpha=0,10$

ns $=$ Tidak signifikan
Tabel 6 menunjukkan variabel yang signifikan berpengaruh terhadap efisiensi teknis usahatani cabai lahan sawah di lereng G unung M erapi adalah penyuluhan. Kegiatan penyuluhan pada wilayah tersebut lebih sering dilakukan oleh petugas dari produsen benih dan pestisida sehingga tidak efektif dan berdampak negatif terhadap produksi cabai. Petugas dari produsen benih lebih sering fokus pada penjualan produk sebanyak-banyaknya daripada membantu mengatasi berbagai masalah petani. U ntuk itu, diperlukan peran petugas penyuluh dari dinas untuk memberikan informasi dan wawasan kepada petani mengenai SO P G ood A griculture Pratice (GAP) budidaya cabai yang tepat.

\section{TABH 7. FAKITRYANGMEME NGARH TTSENB TENSUSA-AAN CABA DLA-ANPASRPANIA}

\begin{tabular}{|c|c|c|c|}
\hline Variabed & kofiser & StandarEro & t-Ratic \\
\hline Kanstata & $-1,067$ & 0,300 & $-3,560^{1+4+4}$ \\
\hline KentitasPenycluhan & $-0,246$ & 0,140 & $-1,756$ \\
\hline TingkAPenddkanFond & $-0,144$ & 0,258 & $-0,560^{\mathrm{s}}$ \\
\hline Pergalamæ Bensedatai & 0,217 & $0,10 \mathrm{C}$ & 1,98* \\
\hline AdustedR & & & 0,078 \\
\hline PdodblitesFhiturs & & & $2,6 \in 3^{* *}$ \\
\hline
\end{tabular}

Sumber: Analisis Data Primer (2017)

Keterangan:

*** = Signifikan pada $\alpha=0,01$

** = Signifikan pada $\alpha=0,05$

* = Signifikan pada $\alpha=0,01$

ns $=$ Tidak signifikan

Variabel penyuluhan mempengaruhi efisiensi teknis usahatani cabai di lahan pasir pantai namun bernilai negatif. $\mathrm{H}$ al ini terjadi karena sebagian besar penyuluhan dilakukan oleh perusahaan benih, pupuk, ataupun pestisida sehingga tidak mencakup seluruh aspek budidaya cabai yang benar tetapi lebih bermotif ekonomi yaitu agar produk dari perusahaan dibeli oleh petani. Pada akhirnya petani juga menggunakan sarana produksi melebihi dosis yang dianjurkan SO P GAP tanaman cabai. U ntuk itu, peran D inas Pertanian dan Petugas Penyuluh Lapangan perlu ditingkatkan untuk mendampingi petani terutama terkait teknologi budidaya. $\mathrm{H}$ al ini sangat penting karena optimali sasi teknologi dan inovasi mampu meningkatkan produksi pertanian cabai di lahan pasir pantai (Kusumaningrum, Foor, \& Mustafa, 2015).

Variabel selanjutnya yang mempengaruhi efisiensi teknis usahatani cabai di lahan pasir pantai adalah pengalaman petani. Pengalaman membuat petani semakin memahami karakteristik tanaman cabai sehingga dapat menentukan 
teknologi budidaya dengan tepat. U ntuk meningkatkan pengalaman petani sebenarnya tidak perlu harus menunggu bertahun-tahun sampai petani menjadi ahli namun dapat dilakukan dengan mengikuti berbagai kegiatan pendidikan terkait teknologi usahatani cabai. Pendidikan memiliki pengaruh sangat kuat untuk meningkatkan efisiensi produksi pertanian dan mempengaruhi petani cabai dalam mengambil keputusan serta kemampuan petani dalam mencari informasi penggunaan faktor produksi dengan tepat (Shanmugam \& Venkataramani, 2006 dan Sukiyono, 2005). Variabel tingkat pendidikan formal tidak berpengaruh terhadap efisiensi teknis usahatani cabai di lahan pasir pantai.

\section{KINERJ A USAHATANI CABAI}

A nalisis pertama untuk mengetahui kinerja usahatani adalah dengan mengitung total biaya usahatani cabai. Biaya usahatani cabai terdiri dari biaya tetap dan biaya variabel.

Kontribusi biaya tetap usahatani cabai terbesar berasal dari biaya lain-ain yaitu biaya sewa lahan, pajak tanah dan penyusutan alat. Struktur biaya ini juga menunjukkan karakteristik usahatani di masing-masing wilayah. Karakteristik pertama terkait dengan kepemilikan lahan petani. Petani cabai di lahan sawah lereng G unung M erapi sebagian besar memiliki tanah sendiri atau meminjam dengan skema pembayaran berupa bagi hasil. Sedangkan sebagian petani lahan pasir pantai menyewa lahan sehingga biaya sewa juga sangat besar.

Karakteristik kedua adalah jumlah alat mesin yang dimiliki petani. Semakin banyak alat mesin yang dimiliki petani maka semakin besar biaya penyusutan. Petani lahan pasir pantai memiliki alat mesin lebih banyak daripada petani cabai di lahan sawah lereng Gunung M erapi. Hal ini karena pengolahan lahan pasir pantai lebih sulit dan harus menggunakan bantuan al at mesin pertanian. $\mathrm{H}$ ampir seluruh petani di lahan pasir pantai memiliki handsprayer manual untuk mengolah lahan. Biaya penyusutan handsprayer merupakan yang terbesar dibandingkan peralatan lain yang dimiliki oleh petani.

Selanjutnya dari struktur biaya variabel, petani di lahan pasir pantai mengalokasikan sebagian besar biaya untuk pembelian sarana produksi sedangkan petani di lahan sawah lereng $G$ unung $M$ erapi untuk biaya lain-lain (bagi hasil sakap). Biaya sarana produksi petani cabai lahan pasir pantai utamanya untuk membeli pupuk, terutama pupuk organik. Penggunaan pupuk merupakan kebutuhan sangat penting karena lahan pasir pantai Kulon Progo kurang subur. Sementara itu, petani cabai di lereng Gunung M erapi harus membayar biaya bagi hasil sangat besar karena lahannya sempit dan meminjam lahan milik orang lain. Rasio bagi hasil petani dengan pemilik lahan adalah 50:50. Nilai ini sangat besar padahal luas lahan yang disakap petani lebih kecil dibandingkan luas lahan yang disewa, namun biaya sakap lebih besar dibandingkan dengan biaya sewa lahan.

\section{TAB⿴囗十 BAAABAABAALUAHAAN CABA D LAHANSAAHIEENG GNNGMEAP DANLAYANPASRPANTA 円RHEXAR}

\begin{tabular}{|c|c|c|c|}
\hline $\mathrm{Nb}$ & JerisBaya & $\begin{array}{r}\text { LahenSanthlereng } \\
\text { CanugMera } \\
\text { (Senar) }\end{array}$ & $\begin{array}{r}\text { LatenPair } \\
\text { Patai (Kulon } \\
\text { Pogo) }\end{array}$ \\
\hline \multicolumn{4}{|c|}{ BayaTetap(Fixed Cost) } \\
\hline \multirow[t]{4}{*}{1} & Bayalainlain(Ro) & 4308310 & 6526.151 \\
\hline & a Sentaldran(Rd) & 3421333 & 5392156 \\
\hline & b PajkTanh(Ro) & 270.80 & 47.058 \\
\hline & c Penyestan(Ro) & $6 / 6177$ & 1086.937 \\
\hline \multicolumn{2}{|c|}{ Tdd BayaTelap(Rp) } & 4.308310 & 6526.151 \\
\hline \multicolumn{4}{|c|}{ Baja Veriabd (Variable Cost) } \\
\hline \multirow[t]{3}{*}{1} & TeragaКeja(RP) & 7.89285 & 9.832960 \\
\hline & a LuerKduaga(Rd) & 6920.85 & 9.264 .986 \\
\hline & $\begin{array}{l}\text { b SeraAatMesin } \\
\text { Petarian(Rp) }\end{array}$ & $9 / 200$ & 567.974 \\
\hline \multirow[t]{13}{*}{2} & SraraPodks (Rp) & $7.9085 / 3$ & 10855556 \\
\hline & a Berih(Rp) & 1700.47 & 2782026 \\
\hline & b Pak(Ro) & 4913080 & 7.041275 \\
\hline & Utea(RP) & 0 & 万.294 \\
\hline & $\Phi(\mathrm{RP})$ & 46100 & 284641 \\
\hline & $\mathrm{KC}(\mathrm{RO})$ & 13366 & 195.098 \\
\hline & $\mathbb{Z}(\mathrm{RP})$ & 124,413 & 496111 \\
\hline & NPKPhonda(RP) & 874767 & 55.222 \\
\hline & NPKMtiaa(Ro) & 1428533 & 1175.882 \\
\hline & Oggrik(RP) & 2305.600 & 4.257 .026 \\
\hline & c Pestisca(Rp) & 1295.06 & 1012255 \\
\hline & $\operatorname{Car}(\mathrm{RP})$ & 100066 & 67.288 \\
\hline & Padtt(BO) & 294.400 & 354.967 \\
\hline \multirow[t]{3}{*}{3} & Láma(Ro) & 12817.333 & 4.65847 \\
\hline & a Bagi Hbil Panen(Ro) & 12810.000 & 0 \\
\hline & b Pergairan(Rp) & 7.333 & 4.658 .471 \\
\hline \multicolumn{2}{|c|}{ Tda Bayalariadad (Rp) } & 28.68764 & 25326986 \\
\hline \multicolumn{2}{|c|}{ Tdd Baya(Ro) } & 32927.074 & 31853137 \\
\hline
\end{tabular}

Sumber: Analisis Data Primer (2017)

Biaya pengairan di lahan pasir pantai lebih tinggi daripada lahan sawah lereng $G$ unung M erapi. Pengairan di lahan pasir pantai dilakukan secara intensif karena di lahan tersebut 
infiltrasi air ke lapisan dalam tanah dan tingkat penguapan lebih tinggi. Kondisi tersebut membuat tanaman cabai cepat mengalami kekeringan sehingga petani lahan pasir pantai lebih sering menggunakan pompa air. D engan begitu, maka petani lahan pasir pantai lebih banyak membeli bahan bakar guna menggerakkan pompa air. Kondisi ini berbeda dengan lahan sawah di lereng Gunung M erapi yang irigasinya sudah baik sehingga petani hanya membayar iuran air.

Pengeluaran selanjutnya usahatani cabai adalah biaya tenaga kerja. Alokasi biaya tenaga kerja luar keluarga utamanya untuk aktivitas pengolahan lahan dan panen. U ntuk alokasi biaya sewa alat mesin pertanian sawah di lereng Gunung Merapi lebih besar daripada lahan pasir pantai karena petani cabai di lereng Gunung M erapi memiliki keterbatasan kepemilikan al at mesin sehingga harusmenyewa, baik kepada individu lain maupun kelompok tani.

Analisis terakhir untuk mengetahui kinerja usahatani adalah menganalisis kelayakan usahatani cabai. Tabel 9 menunjukkan bahwa petani di kedua wilayah sama-sama mampu menghasilkan penerimaan lebih tinggi daripada biaya usahatani. D engan kata lain, usahatani cabai di kedua wilayah memang menguntungkan petani (Satyarini, 2009; Saputro, Kruniasih \& Subeni, 2013 dan Istiyanti, Khasanah, \& Anjarwati, 2015).

\section{TABH 9 PEBANDNGANPENDAPATNDANKBAAKANUSAHAAN CABA PADALAHANSAMAHIEENGGNNGMEAP DFNGNLAHANPASR PANTA PRREKTR}

\begin{tabular}{|c|c|c|c|}
\hline Nb & Kterangen & 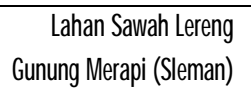 & $\begin{array}{l}\text { LdanParirPata } \\
\text { (KlonProg) }\end{array}$ \\
\hline \multirow[t]{3}{*}{1} & Pereinæan(Ro) & 5982416 & 87.982358 \\
\hline & Podks (kg) & 3102,93 & 6624,18 \\
\hline & HagaRodkperkg(Ro) & 19.289 & 13282 \\
\hline \multirow[t]{6}{*}{2} & Baja & & \\
\hline & Baya Teqp(Rp) & 4308310 & 6.52615 \\
\hline & BayaVaidad (Rp) & 2868764 & 25326986 \\
\hline & Toda Basa(R) & 32927.074 & 3183313 \\
\hline & Perceptan $(\mathrm{PO})$ & 26953342 & 5612927 \\
\hline & RKCräo & 1,82 & 2,76 \\
\hline
\end{tabular}

Sumber: Analisis Data Primer (2017)

A pabila dibandingkan dengan analisis tabel, dapat diketahui bahwa terdapat perbedaan penerimaan, biaya, pendapatan dan kelayakan usahatani antar kedua wilayah. Tabel 9 menunjukkan bahwa penerimaan, pendapatan dan kelayakan usahatani lahan pasir pantai lebih tinggi daripada lahan sawah di lereng Gunung M erapi. Kondisi ini terjadi karena tingkat produksi dan efisiensi teknis usahatani cabai lahan pasir pantai juga lebih tinggi daripada lahan sawah.

$H$ arga jual cabai di Sleman sebenarnya lebih tinggi namun fluktuasinya juga tinggi sedangkan harga jual cabai di Kulon Progo relatif lebih stabil. $\mathrm{H}$ arga jual cabai di Sleman saat penelitian lebih tinggi daripada tahuntahun sebelumnya karena pada tahun 2017 Pemkab Sleman bekerjasama dengan Bank Indonesia membentuk pasar lelang cabai di Kecamatan N gemplak. Pasar lelang ini mampu mengatasi fluktuasi harga di Sleman pada tahun 2017. Fluktuasi harga cabai sebenarnya dapat dikurangi saat petani melakukan pengolahan hasil sehingga menjamin ketersediaan stok cabai baik di masyarakat secara umum maupun petani secara khusus. Pengolahan hasil juga mampu meningkatkan keuntungan bagi petani dan nilai tambah produk pertanian sampai di atas 40\% (Priantara, Mulyani, \& Satriawan, 2016).

Petani lahan pasir pantai menjual produksi cabai kepasar lelang karena efektivitas fungsi pemasaran dari pengelola pasar lelang. Efektivitas tersebut didukung dengan adanya sistem manajemen yang meliputi perencanaan produk, sistem penetapan harga, distribusi fisik, periklanan dan promosi serta penjualan yang baik (Rusdiyana, 2015). D ari hasil penelitian ini, terbukti pasar lelang mampu memberikan keuntungan petani dan menstabilkan harga jual cabai. Pasar lelang mampu menjamin terjualnya produk dalam jumlah besar dengan harga yang menguntungkan bagi petani dan pedagang (Prabhavathi, Krishna, \& Seema, 2013; Devi, H arsoyo \& Subejo, 2015). Di dalamnya juga terdapat negosiasi antar pelaku pemasaran. Selain itu, pasar lelang juga mampu meningkatkan kerja sama anggota sehingga dapat mengembangkan kelompok taninya (Fauziah, 2017).

Dengan melihat keunggulan pasar lelang, maka petani cabai sewajarnya menyelenggarakan pasar lelang untuk menjalin kemitraan dengan berbagai pihak terutama mengenai jaminan pasar. Petani dapat bermitra dengan perusahaan pengolah hasil cabai. Petani juga dapat bermitra dengan pedagang melalui fasilitas yang disediakan pemerintah seperti Stasiun Terminal A gribisnisataupun lainnya. Penguatan dan pengembangan kemitraan terbukti merupakan cara peningkatan daya saing pertanian cabai (Tsurayya \& Kartika, 2015).

\section{KESIMPULAN}

Penggunaan sarana produksi, kuantitas produksi, efisiensi teknis, pendapatan dan kelayakan usahatani cabai lahan pasir 
pantai lebih tinggi daripada lahan sawah di lereng Gunung M erapi. Produksi cabai di lereng $G$ unung $M$ erapi dipengaruhi luas lahan, tenaga kerja, benih, pupuk ZA, pestisida Bion M dan petani dalam kondisi inefisiensi teknis sedangkan produksi cabai di lahan pasir pantai dipengaruhi luas lahan, pupuk TSP, pupuk organik dan petani dalam kondisi inefisiensi teknis. Efisiensi teknis usahatani cabai di lahan pasir pantai dipengaruhi oleh kuantitas penyuluhan dan pengalaman petani sedangkan efisiensi teknis usahatani cabai lahan sawah di lereng $G$ unung $M$ erapi dipengaruhi kuantitas penyuluhan. Pasar lelang di kedua wilayah juga terbukti mampu meningkatkan harga cabai sehingga dapat menjadi percontohan bagi wilayah lain. U ntuk pengembangan usahatani cabai di kedua wilayah diperlukan peran aktif petugas penyuluh lapangan untuk mendampingi petani terutama terkait teknologi budidaya dan pengolahan cabai.

\section{DAFTAR PUSTAKA}

Adhikari, R. K. (2011). Economics of Organic Rice Production. The Journal of Agriculture and Environment, 12(1), 97-103.

Al-Omran, A. M., Falatah, A. M., Sheta, A. S., \& Al-Harbi, A. R. (2004). Clay Deposits For Water Management of Sandy Soils. Arid Land Research and Management, 18(2), 171-183. https://doi.org/10.1080/ 15324980490280825

Andayani, S. A. (2016). Faktor-faktor yang Menentukan Produksi Cabai Merah. M imbar Agribisnis, 1(3), 261-268.

Bank Indonesia. (2007). Pola Pembiayaan Budidaya Cabai Merah (Syariah). Jakarta: Direktorat Kredit Bank Indonesia.

Coelli, T. J., Rao, D. S. P., O'Donnell, C. J., \& Battes, G. E. (2005). An Introduction to Efficiency and Produtivity Analysis. Second Edition. Brisbane: Univesity of Queensland.

Devi, P., Harsoyo., \& Subejo. (2015). Keefektifan Lembaga Pasar Lelang Cabai Merah di Kecamatan Panjatan, Kabupaten Kulon Progo, Agro Ekonomi, 26 (2), 139-149.

Dinas Pertanian Provinsi Daerah Istimewa Yogyakarta. (2009). Standard Operating Procedure (SOP) Budidaya Cabai Merah Kulon Progo. Yogyakarta: Dinas Pertanian Provinsi Daerah Istimewa Yogyakarta

Fauziah, F. (2017). Respons Petani Lahan Pasir Pantai terhadap Pemasaran Sistem Lelang Cabai di Kecamatan Panjatan, Kabupaten Kulon Progo. Yogyakarta. Prosiding Seminar Nasional M asyarakat Biodiversity Indonesia, (pp. 94-98). Surakarta: Universitas Sebelas M aret. https://doi.org/ $10.13057 / \mathrm{psnmbi} / \mathrm{m030116}$

Istiyanti, E. (2010). Efisiensi Pemasaran Cabai M erah Keriting di Kecamatan Ngemplak Kabupaten Sleman. Jurnal Pertanian Mapeta, 12(2), 116124.

Istiyanti, E., Khasanah, U., \& Anjarwati, A. (2015). Pengembangan Usahatani Cabai Merah di Lahan Pasir Pantai Kecamatan Temon Kabupaten Kulon Progo. AGRARIS: Journal of Agribusiness and Rural Development Research, 1(1), 6-11. https://doi.org/10.18196/agr.112.

Kadek, I. P., Fanani, Z., \& Hartono, B. (2015). Analysis of Financial Broiler Farming Open House System Partnership at Sinar Sarana Sentosa, Ltd. Malang Region. IOSR Journal of Agriculture and Veterinary Science (IOSR-JAVS), 8(12), 77-86. https://doi.org/10.9790/2380-081217786.

Kementrian Pertanian Indonesia. (2010). Pupuk dan Pemupukan Budidaya Cabai. Hortikultura, Pusat Penelitian dan Pengembangan. Jakarta: Balai
Pengkajian Teknologi Pertanian Aceh Kementerian Pertanian.

Kuntadi, E. B., \& Jamhari. (2012). Efisiensi Pemasaran Cabai M erah M elalui Pasar Lelang Spot di Kabupaten Kulon Progo, Yogyakarta. Jurnal Sosial Ekonomi Pertanian, 1(1), 95-101.

Kusumaningrum., Foor, J. Z., \& Mustafa, D. (2015). Social Quality Masyarakat Lahan Pasir Pantai pada Aspek Social Empowerment di Kecamatan Panjatan Kabupaten Kulon Progo. Agriekonomika, 4(1), 1-9.

Marr, A., Winkel, A., Asseldonk, M., Lensink, R., \& Bulte, E. (2016). Adoption and Impact of Index-Insurance and Credit for Smallholder Farmers in Developing Countries. Agricultural Finance Review, 76(1), 94118.

Nadezda, J., Dusan, M., \& Stefania, M. (2017). Risk Factors in the Agriculture Sector. Agricultural Economics (Zemìdilská Ekonomika), 63(6), 247-258. https://doi.org/10.17221/212/2016-AGRICECON.

Ouattara, W. (2012). Economic Efficiency Analysis in Côte d'Ivoire. American Journal of Economics, 2(1), 37-46. https://doi.org/10.5923/ j.economics.20120201.05.

Prabhavathi, Y., Krishna, N. T., \& Seema, D. (2013). Analysis of Supply Chain of Spices in India: A Case Study of Red Chillies. International Journal of Scientific and Research Publications, 3(9), 1-4. Retrieved from http://www.ijsrp.org/research-paper-0913/ijsrp-p21101.pdf.

Priantara, I. D. G. Y., Mulyani, S., \& Satriawan, I. K. (2016). Analisis Nilai Tambah Pengolahan Kopi Arabika Kintamani Bangli. Jurnal Rekayasa dan Manajemen Agroindustri, 4(4), 33-42.

Rusdiyana, E. (2015). Manajemen Kelembagaan Pasar Lelang dalam Memfasilitasi Pemasaran Cabai Kelompok Tani Lahan Pasir Pantai Kecamatan Panjatan, Kabupaten Kulon Progo. Jurnal Sungkai, 3(2), 49-64.

Saputro, J., Kruniasih, I., \& Subeni. (2013). Analisis Pendapatan dan Efisiensi Usahatani Cabai Merah di Kecamatan Minggir Kabupaten Sleman. Agros, 15(1), 111-122.

Satyarini, T. B. (2009). Analisis Usahatani Cabai di Lahan Pasir Pantai (Studi Kasus di Pantai Pandan Simo, Bantul, DIY). Prosiding Seminar Nasional Peningkatan Daya Saing Agribisnis Berorientasi Kesejahteraan Petani. Bogor: Pusat Sosial Ekonomi dan Kebijakan Pertanian.

Shanmugam, K., \& Venkataramani, A. (2006). Technical Efficiency in Agricultural Production and Its Determinants: An Exploratory Study at the District Level. Indian Journal of A gricultural Economics, 61(2), 169184. Retrieved from http://ageconsearch.umn.edu/bitstream/204455/ 2/02-Shanmugam.pdf.

Sukiyono, K. (2005). Faktor Penentu Tingkat Efisiensi Teknik Usahatani Cabai Merah di Kecamatan Selupu Rejang, Kabupaten Rejang Lebong. Jurnal Agro Ekonomi, 23(2), 176-190.

Tsurayya, S., \& Kartika, L. (2015). Kelembagaan dan Strategi Peningkatan Daya Saing Komoditas Cabai Kabupaten Garut. Jurnal Manajemen dan Agribisnis, 12(1), 1-13. https://doi.org/10.17358/JMA.12.1.1.

Widodo, A. S. (2015). Pendapatan dan Produksi Potensial Usahatani Konservasi Lahan Pantai di Kabupaten Bantul. AGRARIS: Journal of Agribusiness and Rural Development Research, 1(1), 1-5. https:// doi.org/10.18196/agr.111. 